\title{
Determining Road Lighting Impact on Traffic Stream Characteristics
}

\author{
Ben-Edigbe Johnnie and Kurnia Yuli Astrid
}

Department of Transportation, Faculty of Civil Engineering, Universiti Teknologi, Malaysia

Received 2013-02-26, Revised 2013-04-09; Accepted 2013-07-02

\begin{abstract}
The study is aimed at estimating road lighting impact on traffic stream characteristics; flow, speed, density and headway for an uninterrupted traffic flow. Volume, speed and headway data were collected during daylight, road lighting and dry weather conditions. Flowrate, speed, density and headways were estimated for daylight and road lighting periods; then compared. Since flowrate, free-flow speed, optimum speed critical density and headways during daylight and road lighting periods did not differ significantly: the study concluded that road lighting does not affect traffic stream characteristics significantly.
\end{abstract}

Keywords: Road Lighting, Headway, Flowrate, Speed, Density

\section{INTRODUCTION}

A good highway makes it possible for users to ride safely and comfortably at the design speed day and night. Road lighting provides visibility that helps driver to get enough visual information and makes roadway functional at night. Although vehicles have their own headlights, road lightings are still needed to enhance visibility and minimise conflicts between road users. Road lighting impact studies are rare. Previous studies often relate traffic flow to safety and accident prevention. Only limited studies have been made to investigate effect of road lighting to traffic flowrate. For example, a significant increase in uninterrupted motorway capacity of about $2.5 \%$ was found during nighttime in a Dutch study according to Minderhoud et al. (1997). Capacity was taken as the maximum traffic flow traversing a section of the motorway per hour under prevailing conditions. A capacity estimation method based on extrapolation of the free-flow rate and density was used. The method assumes that the density at capacity is not affected by illumination, which implies that capacity shifts are fully the result of speed changes. Since the study is dependent on a fixed motorway section, it can be affirmed that such section will be subjected to a $24 \mathrm{~h}$ time period. Daylight can reasonably be taken as $7 \mathrm{am}$ to $7 \mathrm{pm}$ and night time taken as $7 \mathrm{pm}$ to 7 am say. Night time is often characterized by off peak traffic flow and it is unlikely that capacity during road lighting will occur at off peak period except of course in extra ordinary circumstances like festival, accident and other extreme ambient conditions. Given that daylight and night time occur at different time periods, the ensuring capacities would be exclusive. Consequently, motorway capacity cannot be said to have increased or decreased significantly due to road lighting. It can be argued. Given the uniqueness of time frame, it is reasonable to estimate travel speed and the extent to which it has been affected by road lighting. In any case, the concern of the study is to estimate the volume of vehicles passing a road section and their corresponding speeds, during daylight, road lighting, dry weather and off-peak conditions.

\subsection{Traffic Stream}

\subsubsection{Characteristics}

According to Ben-Edigbe (2010) road capacity estimation consists of a series of essential points of interest that include among others; Type of Data To Be Collected, Location Choice for Observations, Choice for Appropriate Averaging Interval, Needed Observation Period, Required Corresponding Author: Ben-Edigbe Johnnie, Department of Transportation, Faculty of Civil Engineering, Universiti Teknologi, Malaysia 
Traffic State and Lane. Further, Ben-Edigbe (2010) postulated that capacity from empirical studies that can be estimated using various methods that include the followings, (i) Estimation with headways; (ii) Estimation with traffic flows (Bi-Modal Distribution Method, Selected Maximal method, Expected Extreme Value Method); (iii) Estimation with traffic flows and speeds using Product limit Method; and (iv) Estimation with traffic flows, speed and density relationship (fundamental diagram). Only the headway and estimation with traffic flows, speed and density methods can be used for off-peak capacity modeling. Since the study is interested in off-peak traffic stream characteristics on road section under daylight, road lighting and dry weather conditions, capacity estimation by way of traffic flow (q), speed (u) and density (k) relationship can be used and written as Equation 1:

$$
\mathrm{q}=\mathrm{uk} \Rightarrow \mathrm{u}-\frac{\mathrm{q}}{\mathrm{k}} \Rightarrow \mathrm{k}=\frac{\mathrm{q}}{\mathrm{u}}
$$

However, the equations below are also used for capacity estimation in the headway distribution method Equation 2-4:

$$
\begin{aligned}
& \mathrm{h}_{\mathrm{m}}=\sum \mathrm{h}_{\mathrm{p}} / \mathrm{n} \\
& \mathrm{q}=\mathrm{n} / \mathrm{T}=1 / \mathrm{h}_{\mathrm{m}}
\end{aligned}
$$

$\mathrm{q}=3,600 / \mathrm{h}_{\mathrm{m}}$

Where:

$h_{p}=$ Time of headway vehicle $p$ to preceding vehicle (sec per vehicle)

$\mathrm{h}_{\mathrm{m}}=$ Mean time headway (sec per vehicle)

$\mathrm{q}=$ Intensity: and

$\mathrm{n}=$ Total number of vehicles passing the measuring point during time $\mathrm{T}$

\subsection{Fundamental Diagram}

The use of fundamental diagram offers four advantages that other methods lack. First the traffic state can be determined at any point required; this gives full information required to assess traffic performance. Secondly, data need not be acquired at a bottleneck location to see the state of traffic at capacity and thirdly, two variables suffice to construct the fundamental diagram. The third parameter is derived from the continuum theory of traffic flow and finally the fundamental diagram approach could be used to model different conditions of the flow. Greenshield speed/density linear model is useful in accuracy of highway capacity prediction according to Mayeur et al. (2010), Ben-Edigbe and Ferguson (2005) and others. The relationship between speed and density is such that as density increases speed decreases:

$\mathrm{u}_{\mathrm{s}}=\mathrm{u}_{\mathrm{f}}-\frac{\mathrm{u}_{\mathrm{f}}}{\mathrm{k}_{\mathrm{j}}} \mathrm{k}$

Where:

$\mathrm{u}_{\mathrm{s}}=$ The space mean speed

$\mathrm{u}_{\mathrm{f}}=$ Free flow speed

$\mathrm{k}=$ The density

$\mathrm{k}_{\mathrm{j}}=$ The density at jam

If Equation 5 is plugged into Equation 1, the flowdensity function can be written as:

$\mathrm{q}_{\mathrm{m}}=-\mathrm{c}+\mathrm{ak}-\mathrm{bk}^{2}$

The draw back with flow-density estimation method lies with determining the critical density. It can be derived, estimated or assumed as appropriate or extrapolated mathematically according to Minderhoud et al. (1997) and Ben-Edigbe (2010). Since our interest is in estimating maximum flow, the choice of precise value of critical density need not be very critical to the outcome of this study. By computing maximum flow for each road segment, it is recognized that capacity varies per road section. In other to derive maximum flow from Equation 6, differentiae flow wrt density as shown below Equation 7 :

$$
\begin{aligned}
& \frac{\partial \mathrm{q}}{\partial \mathrm{k}}=\mathrm{a}-2\left(\frac{\mathrm{a}}{\mathrm{k}_{\mathrm{j}}}\right) \mathrm{k} \Rightarrow \text { critical densilty, } \mathrm{k}_{0} \mathrm{k}_{0}=\frac{\mathrm{a}}{2\left(\frac{\mathrm{a}}{\mathrm{k}_{\mathrm{j}}}\right)} \\
& \text { then, } \mathrm{u}=\mathrm{a}-\frac{\mathrm{a}}{\mathrm{k}_{\mathrm{j}}}\left(\frac{\mathrm{a}}{2\left(\frac{\mathrm{a}}{\mathrm{k}_{\mathrm{j}}}\right)}\right)
\end{aligned}
$$

Maximum flow Equation 8:

$$
\mathrm{q}_{\mathrm{m}}=\mathrm{ak}-\frac{\mathrm{a}}{\mathrm{k}_{\mathrm{j}}}\left(\frac{\mathrm{a}}{2\left(\frac{\mathrm{a}}{\mathrm{k}_{\mathrm{j}}}\right)}\right)^{2}
$$


Optimum speed Equation 9:

$$
\mathrm{v}_{0}=\frac{\mathrm{ak}-\frac{\mathrm{a}}{\mathrm{k}_{\mathrm{j}}\left(\frac{\mathrm{a}}{2\left(\frac{\mathrm{a}}{\mathrm{k}_{\mathrm{j}}}\right)}\right)}}{\frac{\mathrm{a}}{2\left(\frac{\mathrm{a}}{\mathrm{k}_{\mathrm{j}}}\right)}}
$$

Since traffic theory is dependent on fundamental diagram, it follows that Equation 10:

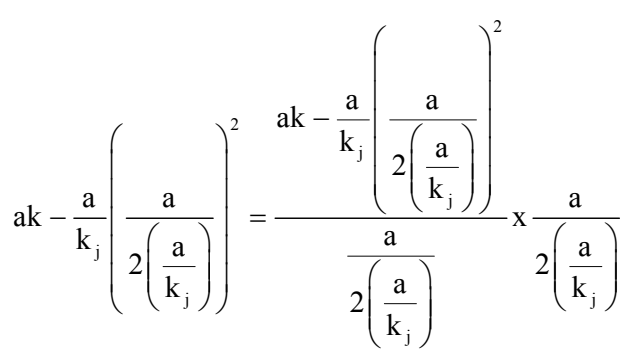

Since passenger car equivalent (pce) measures the impact that a mode of transport has on traffic variables compared to a passenger car under prevailing conditions, it follows that changes in prevailing conditions will have relative effect on pce values. In essence pce values are dynamic; consequently, pce values were estimated using a simple model equation shown below in Equation 11 . So, there is no need to build a need model.

$$
\text { pce }_{i j}=\frac{h_{i j}}{h_{p c j}}
$$

For pce $_{\mathrm{ij}}=$ pce of vehicle Type $\mathrm{i}$ under Conditions $\mathrm{j}$ : and $h_{i j}, h_{p c j}=$ average headway for vehicle Type $i$ and passenger car for Conditions $\mathrm{j}$. In any case, the study pce values though useful have not affected the study outcomes significantly. Note that PCE is usually the terminology employed in the United States and Canada, while PCU is commonly used in the United Kingdom.

\subsection{Data Collection}

In order to collect traffic stream data, $24 \mathrm{hr}$ automatic traffic counters were installed at two sites in Skudai, Malaysia for 8 weeks. Three classes of vehicles (passenger cars, large goods vehicle and heavy goods vehicle) were investigated. It is important that influences from intersection and other attraction on collected data are minimised. Intersections are kept at distances greater than an estimated stopping sight distance for the road segment. The intersection Stopping Distance (SSD) was based on Equation 12 below, with assumptions of 5\% road gradient, $2.5 \mathrm{sec}$ reaction time and 0.3 coefficient of friction:

$\mathrm{SSD}=0.278 \mathrm{v}_{\mathrm{t}}+0.039 \frac{\mathrm{v}^{2}}{\mathrm{a}}$

$\mathrm{t}=$ Brake reaction time

$\mathrm{V}=$ Speed, $\mathrm{km} / \mathrm{h}$

$\mathrm{a}=$ Deceleration rate

Typical setup of road lighting impact study site is shown below in Fig. 1.

\subsection{Analysis and Findings}

In this study, maximum flow was based on extrapolation from speed and density linearity function. The reasons for this approach are; (i) comparative capacity for prevailing conditions are dependent on same $24 \mathrm{hr}$ time frame; (ii) road lighting and daylight are with the same $24 \mathrm{~h}$ time frame; (iii) if predicted maximum flow would result from speed changes; where flow, speed, density and headway are readily available, why not compare these parameters rather than use a single parameter (capacity) from different time frame; (iv) speed normalization would allow maximum flow boundary to gyrate within the allowable speed variance. It can be argued that critical volume to capacity ratio $(\mathrm{x} / \mathrm{q})$ is often taken as 0.85 . It means that speed reduction is not precisely limited to optimum speed; rather allowance for speed variance must be accommodated for in the analysis. Hence in other for any significant road capacity loss to occur, such reduction must occur outside the variance envelope. Therefore if this line of thought is pursued, the resultant $2.5 \%$ capacity loss in the Dutch case study will be inconsequential. It can be argued. In any case, aggregated data collected at road sections were analysed for each prevailing condition using a stepwise procedure:

Step 1: Determine traffic volume and speed profile for the road segment under observation. Typical volume-density scatter plot for Skudai road segment is shown below in Fig. 2

Step 2: Estimate traffic flows using appropriate pce values

Step 3: Estimate vehicle speeds variances and associated errors per road section, then divide flow by speed to compute density. Compute free-flow headways using Equation 4 as shown in Table 1.

Step 4: Develop a model for flow/density relationship, test for validity as shown below in Table 2 


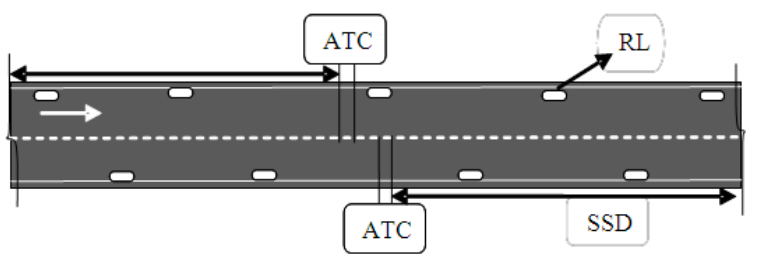

Fig. 1. Typical Layout of Survey site

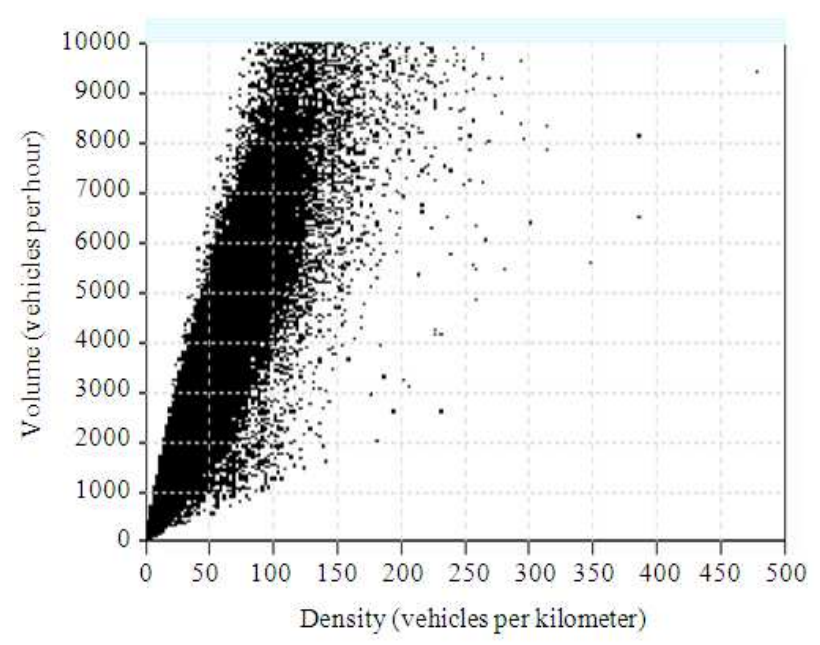

Fig. 2. Typical volume-density scatter plot

The model coefficients in equations have the expected signs and the coefficients of determinations $\left(\mathrm{R}^{2}\right)$ are much greater than 0.85 ; so it can be suggested that a strong relationship between flows and densities exists and the model could be used to estimate roadway capacity for the link sections. The Fobserved statistics at 10 degree of freedom is much greater than $\mathrm{F}$ critical (4.94) suggesting that the relationship did not occur by chance. Also the tobserved statistic at 10 degree of freedom tested at $5 \%$ significance level is much greater than 2 thus suggesting that density is an important variable when estimating flow. The statistics were taken directly from the spreadsheet output:

Step5: Derive flow/density functions, or as an alternative

Step6: Skip steps 4 and 5, model flow/density relationships directly and test for validity

Step7: Estimate critical densities, hence maximum flow and optimum speeds; Compute congested headways using Equation 4
Table 1a. Flow, Speed and Density data for Site 1

\begin{tabular}{llllll}
\hline Lane 1a & \multicolumn{5}{c}{ Lane 1b } \\
\hline $\mathrm{V}( \pm 10)$ & $\mathrm{q}$ & $\mathrm{k}$ & $\mathrm{V}( \pm 5)$ & $\mathrm{q}$ & $\mathrm{k}$ \\
\hline 61 & 888 & 14.56 & 57 & 744 & 13.05 \\
57 & 1362 & 24.12 & 60 & 528 & 8.80 \\
54 & 1560 & 28.87 & 52 & 804 & 15.46 \\
49 & 2112 & 43.17 & 57 & 642 & 11.26 \\
47 & 1896 & 39.92 & 50 & 936 & 18.72 \\
36 & 2526 & 70.41 & 45 & 1224 & 26.90 \\
41 & 2358 & 57.98 & 50 & 1242 & 24.94 \\
39 & 2352 & 60.86 & 46 & 1230 & 26.45 \\
39 & 2556 & 65.10 & 43 & 1302 & 30.28 \\
34 & 2694 & 79.08 & 45 & 1152 & 25.60 \\
31 & 2574 & 82.52 & 55 & 816 & 14.84 \\
38 & 2736 & 72.31 & 50 & 1194 & 23.93 \\
\hline Note: $(\mathrm{v})$ Speed km/hr· $(\mathrm{q})$ Flow veh/hr. (k) Density veh/km
\end{tabular}

Note: (v) Speed km/hr.: (q) Flow veh/hr.: (k) Density veh/km

Table 1b. Flow, Speed and Density data for Site 2

\begin{tabular}{|c|c|c|c|c|c|}
\hline \multicolumn{3}{|l|}{ Lane $2 \mathrm{a}$} & \multicolumn{3}{|c|}{ Lane $2 b$} \\
\hline $\mathrm{V}( \pm 10)$ & $q$ & $\mathrm{k}$ & $\mathrm{V}( \pm 5)$ & $q$ & $\mathrm{k}$ \\
\hline 62 & 228 & 3.68 & 58 & 1218 & 20.87 \\
\hline 18 & 1500 & 83.33 & 62 & 1356 & 21.87 \\
\hline 44 & 1224 & 27.82 & 56 & 1776 & 31.89 \\
\hline 48 & 1050 & 21.88 & 45 & 1992 & 44.27 \\
\hline 33 & 1260 & 38.18 & 41 & 2352 & 57.37 \\
\hline 53 & 792 & 14.94 & 49 & 1866 & 38.08 \\
\hline 58 & 660 & 11.38 & 40 & 2226 & 55.65 \\
\hline 60 & 564 & 9.40 & 50 & 2178 & 43.56 \\
\hline 55 & 708 & 12.87 & 47 & 2328 & 49.53 \\
\hline 60 & 456 & 7.60 & 56 & 1908 & 34.11 \\
\hline 57 & 570 & 10.00 & 50 & 1866 & 37.32 \\
\hline 60 & 594 & 9.90 & 51 & 1752 & 34.35 \\
\hline
\end{tabular}

Note: (v) Speed km/hr.: (q) Flow veh/hr.: (k) Density veh/km

Table 2. Model coefficients

\begin{tabular}{|c|c|c|c|c|c|}
\hline \multirow[b]{2}{*}{ Site } & \multirow[b]{2}{*}{$\begin{array}{l}\text { Prevailing } \\
\text { conditions }\end{array}$} & \multicolumn{4}{|c|}{ Flow/Density } \\
\hline & & Flow-c & $\begin{array}{l}\text { Speed } \\
\lambda \mathrm{k}\end{array}$ & $\begin{array}{c}\text { Density } \\
-\lambda \mathrm{k}^{2} \\
\end{array}$ & $\mathrm{R}^{2}$ \\
\hline \multirow[t]{2}{*}{1} & Daylight & -47.78 & 92.3 & -0.99 & 0.95 \\
\hline & R-lighting & -76.80 & 92.9 & -0.94 & 0.94 \\
\hline \multirow[t]{2}{*}{2} & Daylight & -28.01 & 88.8 & -0.91 & 0.90 \\
\hline & R-lighting & -28.13 & 85.1 & -0.76 & 0.97 \\
\hline
\end{tabular}

For example; road segment under observation the flow-density model Equation 13 is:

$\mathrm{q}=-1.96+84.9 \mathrm{k}-0.67 \mathrm{k}^{2} \mathrm{R}^{2}=0.95$

$\partial \mathrm{q} / \partial \kappa=2(-0.67 \mathrm{k})+84.9=0$

Critical density, $\mathrm{k}_{\mathrm{c}} @ 63.4 \mathrm{veh} / \mathrm{km}$ 
Table 3. Traffic Stream Characteristics

\begin{tabular}{lllllll}
\hline Site & $\mathrm{PC}$ & $\mathrm{q}_{\mathrm{m}}$ & $\mathrm{U}_{f \mathrm{~km} / \mathrm{h}}$ & $\mathrm{U}_{\mathrm{o} \mathrm{km} / \mathrm{h}}$ & $\mathrm{k}_{\mathrm{c} \mathrm{veh} / \mathrm{km}}$ & $\mathrm{Hwy}_{(\mathrm{s})}$ \\
\hline 1 & $\mathrm{DL}$ & 2103 & 92 & 44.7 & 47 & 1.7 \\
& $\mathrm{RL}$ & 2138 & 89 & 45.4 & 49 & 1.7 \\
2 & $\mathrm{DL}$ & 2218 & 93 & 45.4 & 49 & 1.6 \\
& $\mathrm{RL}$ & 2354 & 85 & 43.9 & 56 & 1.5 \\
\hline
\end{tabular}

Table 4. Differential speed statistics

\begin{tabular}{llll}
\hline Site & PC & $\mathrm{U}_{f} \Delta$ & Tab $\chi^{2}=3.14$ \\
\hline 1 & DL RL & $3 \mathrm{~km} / \mathrm{h}$ & Cal. $\chi^{2}=0.57<3.14$ \\
2 & DL RL & $8 \mathrm{~km} / \mathrm{h}$ & Cal. $\chi^{2}=1.8<3.14$ \\
\hline
\end{tabular}

Then plug $\mathrm{k}_{\mathrm{c}}$ into equation 13 so that:

$\mathrm{q}_{\mathrm{m}}=-0.67(63.4)^{2}+84.9(63.4)-1.96$

Capacity, Q $=2688 \mathrm{veh} / \mathrm{hr}$.,

Optimum speed, $\mathrm{u}_{\mathrm{o}}=2688 / 63=42 \mathrm{~km} / \mathrm{h}$

Step8: Determine capacities for the road segment in order to make sure that computed traffic flows occurred at off-peak periods as shown below in Table 3.

Step9: Compare headway, speed and maximum flow outcomes as shown below in Table 4. Note: PC denotes prevailing conditions; DLdaylight; RL-road lighting; Hwy-headway; $\Delta$ change. Where; calculated $\chi^{2}=(2151$ $2103)^{2} / 2151=1.07<\mathrm{Tab} \chi^{2}=3.14$ it can be postulated that there is no significant difference in computed maximum flows

The impact study was carried out to determine the extent of road lighting impact on traffic flow characteristics. Average roadway capacity during daylight is approximately $2096 \mathrm{pcu} / \mathrm{hr} / \mathrm{ln}$ and $2154 \mathrm{pcu} / \mathrm{hr} / \mathrm{ln}$ under road lighting. The capacity differential is about $3 \%$ and insignificant. It can be seen from Table 4 above that freeflow speeds for daylight and road lighting are within speed variance of $12 \%$; hence they cannot be construed as significant. Since there is nothing in the study to suggest that change in maximum flow occurred because of road lighting, it can be postulated that increase in demand flow is responsible. Take note that the changes in headways are negligible. In sum, the study has shown that traffic stream characteristics for daylight and road lighting conditions can be computed and compared.

\section{CONCLUSION}

Based on the synthesis of evidences obtained from the assessment of traffic stream characteristics under daylight and road lighting conditions, the study concluded that:
- The relationship between flows/densities as well as speeds/densities can be relied on when modeling capacity for road segment

- There is no significant difference between traffic stream characteristics under daylight and road lighting conditions

- The hypothesis that capacity loss would result from road lighting is not valid

\section{REFERENCES}

Ben-Edigbe, J. and N. Ferguson, 2005. Extent of capacity loss resulting from pavement distress. Proc. ICE Transport, 158: 27-32. DOI: 10.1680/tran.2005.158.1.27

Ben-Edigbe, J., 2010. Assessment of speed-flow-density functions under adverse pavement condition. Int. J. Sustain. Dev. Plann., 5.

Mayeur, A., R. Bremon and J.M. Bastien, 2010. Effects of the viewing context on target detection. Implications for road lighting design. J. Applied Ergonom., 41: 461-8. PMID: 19896115

Minderhoud, M.M., H. Botma and P.H.L. Bovy, 1997. Assessment of roadway capacity estimation methods. Transportation Res. Record, 1572: 59-67. DOI: $10.3141 / 1572-08$ 